\title{
Cloning and Functional Characterization of a Novel Dopamine Receptor from Drosophila melanogaster
}

\author{
Guoping Feng, ${ }^{1}$ Frances Hannan, ${ }^{1,2}$ Vincenzina Reale, ${ }^{2}$ Yuen Yi Hon, ${ }^{1}$ Christopher T. Kousky, ${ }^{1}$ \\ Peter D. Evans, ${ }^{2}$ and Linda M. Hall ${ }^{1}$ \\ 1Department of Biochemical Pharmacology, State University of New York at Buffalo, Buffalo, New York 14260-1200, and \\ 2The Babraham Institute Laboratory of Molecular Signalling, Department of Zoology, University of Cambridge, Cambridge \\ CB2 3EJ, United Kingdom
}

\begin{abstract}
A cDNA clone is described that encodes a novel G-proteincoupled dopamine receptor (DopR99B) expressed in Drosophila heads. The DopR99B receptor maps to $99 \mathrm{~B} 3-5$, close to the position of the octopamine/tyramine receptor gene at 99A10$B 1$, suggesting that the two may be related through a gene duplication. Agonist stimulation of DopR99B receptors expressed in Xenopus oocytes increased intracellular $\mathrm{Ca}^{2+}$ levels monitored as changes in an endogenous inward $\mathrm{Ca}^{21}$ dependent chloride current. In addition to initiating this intracellular $\mathrm{Ca}^{2+}$ signal, stimulation of DopR99B increased cAMP levels. The rank order of potency of agonists in stimulating the chloride current is: dopamine $>$ norepinephrine $>$ epinephrine $>$ tyramine. Octopamine and 5-hydroxytryptamine are not active $(<100 \mu \mathrm{M})$. This pharmacological profile plus the second-
\end{abstract}

messenger coupling pattern suggest that the DopR99B receptor is a D1-like dopamine receptor. However, the hydrophobic core region of the DopR99B receptor shows almost equal amino acid sequence identity (40-48\%) with vertebrate serotonergic, $\alpha 1$ - and $\beta$-adrenergic, and D1-like and D2-like dopaminergic receptors. Thus, this Drosophila receptor defines a novel structural class of dopamine receptors. Because DopR99B is the second dopamine receptor cloned from Drosophila, this work establishes dopamine receptor diversity in a system amenable to genetic dissection.

Key words: cloned dopamine receptor; Drosophila melanogaster; Xenopus oocyte expression; adenylyl cyclase; calcium; gene mapping
Dopamine is a neurotransmitter in both the central and the peripheral nervous systems and is involved in a variety of important physiological and behavioral processes, such as neuroendocrine function, emotion, and motor control (Civelli et al., 1993). Moreover, dopaminergic systems have been implicated in several neurological disorders, including Parkinson's disease and schizophrenia (Seeman et al., 1984; Goldstein and Deutch, 1992; Wichmann and DeLong, 1993). Dopamine exerts its effects by interacting with G-protein-coupled, heptahelical membrane receptors on the cell surface (Jackson and Westlind-Danielsson, 1994).

Numerous agonists and antagonists of dopamine receptors have been discovered in the search for new drugs to battle neurological disorders. Using these drugs, dopamine receptors were originally

\footnotetext{
Received Nov. 30, 1995; revised March 26, 1996; accepted April 2, 1996.

This work was supported by National Institutes of Health Jacob Javits Neuroscience Investigator Award NS16204 to L.M.H. and NATO Collaborative Research Grant 900709 to P.D.E. and L.M.H. G.F. was supported, in part, by a predoctoral fellowship from the Pharmaceutical Manufacturers Association Foundation. V.R. was supported, in part, by a grant from the Isaac Newton Trust. C.T.K. was supported by National Institutes of Health training Grant GM07145 and by a Howard Hughes Predoctoral Fellowship. We thank Jane Pursey-Lee for outstanding technical assistance in the initial stages of cloning and sequencing the 0.68 PCR fragment, and Dr. Todd R. Jackman for helpful comments.

Correspondence should be addressed to Linda M. Hall, Department of Biochemical Pharmacology, State University of New York at Buffalo, 329 Hochstetter Hall, North Campus, Buffalo, NY $14260-1200$ (please note that Dr. Hall is on sabbatical until $9 / 30 / 96$. Her sabbatical address should be used for correspondence concerning this manuscript during that time).

Dr. Hall's sabbatical address (9/95 to 9/30/96): Department of Microbiology and Molecular Genetics, Medical Sciences I Bldg C, Room 266, University of CaliforniaIrvine, Irvine, CA $92717-4025$.

Dr. Feng's current address: Department of Anatomy and Neurobiology, Washington University School of Medicine, 660 South Euclid Avenue, St. Louis, MO 63110. Copyright 1996 Society for Neuroscience $0270-6474 / 96 / 163925-09 \$ 05.00 / 0$
}

classified into D1 and D2 subtypes based on their pharmacological specificity with neuroleptics (Kebabian and Calne, 1979), a class of dopamine antagonists used to alleviate the main symptoms of schizophrenia (Lcvinson, 1991). Molccular cloning of dopamine receptors has revealed at least five distinct subtypes (D1-D5) that can be divided into two classes, the D1-like (D1 and D5) and D2-like (D2, D3, and D4) receptors based on their sequence similarity and pharmacological profile (Gingrich and Caron, 1993). These two classes of dopamine receptors are linked to distinct cascades for signal transduction. Activation of D1-like receptors stimulates adenylyl cyclase and phosphatidylinositol4,5-bisphosphate (PI) metabolism, whereas D2-like receptor activation inhibits adenylyl cyclase and activates potassium channcls (Gingrich and Caron, 1993; Jackson and Westlind-Danielsson, 1994).

Dopamine and dopamine receptors have long been thought to play an important role in the invertebrate nervous system (Weiss and Drummond, 1981; Sonetti et al., 1987; Walker and HoldenDye, 1989; Ali and Orchard, 1994; Hall, 1994). We report here the molecular cloning and functional characterization of a novel Drosophila dopamine receptor that shows a pharmacology and second-messenger coupling pattern similar to D1-like receptors. However, this Drosophila receptor differs structurally from the D1-like group of dopamine receptors that includes mammalian D1 and D5 subtypes, and it also differs from a previously reported D1-like receptor from Drosophila (Gotzes et al., 1994; Sugamori et al., 1995). Northern blot analysis suggests that this novel Drosophila receptor is expressed in both central and peripheral nervous systems. Stimulation of these receptors, expressed in Xenopus oocytes, generates a calcium signal and increases cAMP 
levels. Gene mapping provides a first step toward future studies aimed at mutant dissection of the physiological roles of dopamine receptor subtypes in the intact organism, including their possible involvement in memory and learning.

\section{MATERIALS AND METHODS}

$P C R$ amplification for initial isolation of new receptor genomic DNA. The forward primer (OPS3: CATAGCCCTCGACCGGTACT) encodes the cytoplasmic end of the third transmembrane domain of the Drosophila octopamine/tyramine receptor (OctyR99AB) (Arakawa et al., 1990). The reverse primer (OPS4: GGCAGCCAGCAGATGACGAA) encodes the middle region of transmembrane domain VI from this receptor. The PCR template was 300 ng of Drosophila genomic DNA prepared from wildtype Canton-S adult flies (Jowett, 1986). The $100 \mu \mathrm{l}$ PCR mixture contained $0.2 \mathrm{~mm}$ each of deoxyribonucleotide triphosphate, $10 \mathrm{~mm}$ Tris- $\mathrm{HCl}$ buffer, $\mathrm{pH} 8.3,50 \mathrm{mM} \mathrm{KCl}, 1.5 \mathrm{~mm} \mathrm{MgCl}_{2}, 0.001 \%$ gelatin, 0.1 $\mu \mathrm{M}$ of each primer, and 2.5 units of AmpliTaq DNA polymerase (PerkinElmer, Norwalk, CT). PCR was performed under reduced stringency annealing conditions: $94^{\circ} \mathrm{C}$ for $2 \mathrm{~min}, 33^{\circ} \mathrm{C}$ for $2 \mathrm{~min}, 72^{\circ} \mathrm{C}$ for $2 \mathrm{~min}$ for 6 cycles followed by an additional 31 cycles with an annealing temperature of $42^{\circ} \mathrm{C}$ instead of $33^{\circ} \mathrm{C}$. Final extension was $10 \mathrm{~min}$ at $72^{\circ} \mathrm{C}$. PCR products were analyzed by electrophoresis of $10 \mu \mathrm{l}$ of reaction mixture on a $1 \%$ agarose gel.

$D N A$ sequencing. Direct sequencing of the PCR product was performed as described previously (Feng et al., 1995; Zheng et al., 1995) using a Taq Dye Primer Cycle Sequencing kit (Applied Biosystems, Foster City, CA). To facilitate the sequencing of the cDNA clone, nested deletions were used (Henikoff, 1987). Each segment of DNA was sequenced at least twice in both directions. The contig was assembled using Geneworks software (Intelligenetics, Mountain View, CA).

Screening for cDNA clones. The $0.68 \mathrm{~kb}$ fragment from the initial PCR amplification experiment was labeled with $\left[\alpha^{-32} \mathrm{P}\right] \mathrm{dCTP}(\sim 110 \mathrm{TBq} /$ mmol) using the Multiprime DNA labeling system (Amersham, Arlington Heights, IL) and was used to screen a Drosophila head cDNA library (Itoh et al., 1985) in $\lambda$ gt1l, generously provided by Dr. Paul Salvaterra (Beckman Research Institute, Duarte, CA). Four positive clones were identified by high-stringency (Sambrook et al., 1989) screening of $4 \times 10^{5}$ plaque-forming units (pfu). The longest insert $(4 \mathrm{~kb})$ was cut out with EcoRI and subcloned into pBluescript II SK(-) for further analysis. This insert and the gene that encodes it are referred to as DopR99B throughout this paper.

Northern blots. Heads, bodies, and appendages (legs and antennae) were isolated from frozen adult flies (Schmidt-Niclsen et al., 1977). Poly $(\mathrm{A})^{+}$RNA and blots were prepared as described previously (Feng et al., 1995; Zheng et al., 1995). Poly(A) ${ }^{+}$RNA $(10 \mu \mathrm{g} /$ lane) was run on a denaturing, formaldehyde agarose $(0.8 \%)$ gel. Blots were probed with the ${ }^{32}$ P-laheled $0.68 \mathrm{kh}$ PCR fragment added to a final concentration of $10^{6}$ $\mathrm{cpm} / \mathrm{ml}$. After high-stringency washing (Feng et al., 1995; Zheng et al., 1995), blots were exposed to X-ray film for $24 \mathrm{hr}$ at $-70^{\circ} \mathrm{C}$.

In situ hybridization to salivary gland chromosome squashes. The $0.68 \mathrm{~kb}$ PCR fragment was biotinylated, hybridized to larval salivary gland polytene chromosome squashes, and localized using the Gibco (Gaithersburg, MD) Bluegene detection kit as described by Engels et al. (1985) with minor modifications (Feng et al., 1995; Zheng et al., 1995).

Expression in Xenopus oocytes. Sense cRNA was prepared in vitro from the DopR99B clone in the pBluescript II SK $(-)$ vector using I'7 RNA polymerase (Stratagene, La Jolla, CA) after linearizing the plasmid with Not I (Promega, Madison, WI). Transcripts were capped by adding 0.75 units of $\mathrm{m}^{7} \mathrm{G}\left(5^{\prime}\right) \mathrm{ppp}\left(5^{\prime}\right) \mathrm{G}$ (Boehringer Mannheim, Indianapolis, IN) to a standard $150 \mu \mathrm{l}$ transcription reaction (Stratagene kit).

Stage V and VI oocytes from virgin female adult Xenopus laevis were manually separated and placed in sterile ND96 medium [in mM: $\mathrm{NaCl} 96$, $\mathrm{KCl} 2, \mathrm{CaCl}_{2} 1.8, \mathrm{MgCl}_{2}$ 1, HEPES buffer ( $\left.\mathrm{pH} 7.6\right) 5$, containing $2.4 \mathrm{~mm}$ sodium pyruvate, $100 \mathrm{U} / \mathrm{ml}$ penicillin, $0.1 \mathrm{mg} / \mathrm{ml}$ streptomycin, $0.2 \mathrm{mg} / \mathrm{ml}$ gentamycin]. The oocytes were defolliculated enzymatically by incubation in ND96 containing collagenase $(2 \mathrm{mg} / \mathrm{ml})$ for $30 \mathrm{~min}$. Oocytes were then injected with $50 \mathrm{ng}$ of Drosophila DopR99B receptor serise cRNA and incubated at $19^{\circ} \mathrm{C}$ for $2-5 \mathrm{~d}$. Uninjected oocytes were used as controls.

Electrophysiological recordings were made from oocytes using a twomicroelectrode voltage-clamp technique, at a $-60 \mathrm{mV}$ holding potential, to measure oocyte currents (Van Renterghem et al., 1987). Oocytes were continuously superfused with ND96 during the experiments at room temperature, and drugs were added to the superfusate.

cAMP assays. To monitor cAMP levels, individual oocytes were prein- cubated for $30 \mathrm{~min}$ in ND96 plus $100 \mu \mathrm{M}$ isobutylmethylxanthine (IBMX). Experimental oocytes were incubated for a further $30 \mathrm{~min}$ with the desired concentration of agonist in the same medium while control nocytes (to measure hasal cAMP levels) were incubated in parallel in the same medium without agonist. After the incubations, each oocyte was homogenized in $500 \mu \mathrm{l}$ of acidified ethanol, centrifuged to remove particulate matter, and the supernatant was evaporated to dryness in a vacuum centrifuge (Savant, Farmingdale, NY). Each sample was taken up in $60 \mu \mathrm{l}$ of assay buffer and assayed for cAMP using a commercial assay kit (Amersham).

Drugs. The drugs used in the classification of the expressed receptor were obtained from the following sources: dopamine hydrochloride, (-)-norepinephrine hydrochloride, (-)-epinephrine, tyramine hydrochloride, DL-octopamine hydrochloride, 5-hydroxytryptamine hydrochloride, $( \pm)$-isoproterenol hydrochloride, phentolamine hydrochloride, and DL-propranolol were from Sigma (Poole, Dorset, UK); $\quad R(+)$-SKF-38393 $[R(+)$-1-phenyl-2,3,4,5-tetrahydro- $(1 \mathrm{H})-3$ benzazepine-7,8-diol], quineloranedihydrochloride, (-)-quinpirole hydrochloride, PD-128,907 [(+)-(4aR,10bR)-3,4,4a,10b-tetrahydro4-propyl-2H,5H-(1)benzopyrano-(4,3-b)-1,4-oxazin-9-ol-hydrochloride], cis-(Z)-flupenthixol dihydrochloride, $R(+) \mathrm{SCH}-23390 \quad[R(+)-7-$ chloro-8-hydroxy-3-methyl-1-phenyl-2,3,4,5-tetrahydro-1H-3-benzepine hydrochloride], $\mathrm{S}(-)$-sulpiride, spiperone hydrochloride, $(+)$ butaclamol hydrochloride, $\mathrm{S}(-)$-eticlopride hydrochloride, domperidone, (+)-bromocriptine methanesulfonate, ( \pm )-6-chloro-APB $[( \pm)$-6-chloro-7,8-dihydroxy -3-allyl-1-phenyl -2,3,4,5-tetrahydro- $1 \mathrm{H}-3$ benzazepine hydrobromide], $R(+)$-6-bromo-APB $(R(+)$-6-bromo7,8 -dihydroxy-3-allyl-1-phenyl-2,3,4,5-tetrahydro- $1 \mathrm{H}$-3-benzazepine hydro-bromide), ( \pm )-6-chloro-PB $[( \pm)$-6-chloro-7,8-dihydroxy-1phenyl-2,3,4,5-tetrahydro-1H-3-benzazepine hydrobromide], and $( \pm$ PPHT $[( \pm)-2-(N$-phenylethyl- $N$-propyl)amino-5-hydroxytetralin hydrochloride] were from Research Biochemicals (Natick, MA).

\section{RESULTS}

\section{Cloning of a novel Drosophila dopamine receptor}

When we began these studies, cDNAs encoding several G-protein-coupled receptors had been cloned from Drosophila, including a muscarinic acetylcholine receptor (Onai et al., 1989), several serotonergic receptors (Witz et al., 1990; Saudou et al., 1992), and an adrenergic receptor homolog (OctyR99AB) (Arakawa et al., 1990). However, there were no representatives of the dopaminergic receptor family cloned from invertebrates even though the role of dopamine was well established in the invertebrate nervous system.

To expand the group of cloned G-protein-coupled receptors from Drosophila, we used reduced stringency PCR with primers from regions conserved in all biogenic amine receptors. To facilitate the identification of those PCR products that were likely to encode new receptors, we amplified across a region including cytoplasmic loop 3 (between transmembrane domains V and VI). This nonconserved loop varies greatly in length among different G-protein-coupled receptors (Probst et al., 1992), so different size amplification products are expected and would serve to distinguish fragments encoding new receptors from those encoding previously cloned ones. In addition, the amplified region also includes the conserved transmembrane domains IV, V, and part of VI. Because these domains are easily recognized, this allows rapid identification of these amplified fragments encoding G-protein-coupled receptors.

PCR primers were chosen by aligning the amino acid sequence of the Drosophila octopamine/tyramine receptor (OctyR99AB) (Arakawa et al., 1990) with sequences of a subset of previously cloned vertebrate biogenic amine receptors. A forward primer sequence (OPS3) was selected from the region of the Drosophila octopamine/tyramine receptor cDNA that encodes the cytoplasmic end of the third transmembrane domain (amino acids IALDRYW). This included the DRY sequence that is found in almost 
A

CCGAGCAGCAACTGCCGGGGAATTGGAACAGGAACATAATCAGGCACAGGAACAGCAACTGAAACAGGGACTCGCGTCAGCTGCAGCGACACAGCACTGAGTTGCAATGGTGGACGACA 120

ATGGCTCGTCGCCGGAAGTGGAAGGAGCGGAAGGAGCCGGCGCGCCCCTCCTGGCGCTCCTCCGGGTGGATGGGCTCAATCAGACGCAGACCCGTTCTCCCTCGCCGTCGTTCTTCGGCA 240

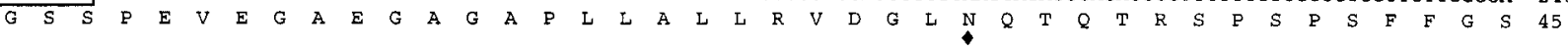

GTTACAACATCTCCGAGGATGTCTACTTCTACTTCAATGGGCTGCCCACGAGCACGGAGCTCGTGCTGAACGCCACCACCTCCGCCACCAGCGCCACCTTGAGTCCTGCGATGGTGGCAA 360

$\begin{array}{llllllllllllllllllllllllllllllllllllllllllll}Y & N & I & S & E & D & V & Y & F & Y & F & N & G & L & P & T & S & T & E & L & V & L & N & A & T & T & S & A & T & S & A & T & L & S & P & A & M & V & A & T & 85\end{array}$

CAGGAGGTGGCGGCACCACCACGCCGGAACCCGATCTCTCCGAGTTCCTGGAGGCGCTGCCCAACGACCGTGTGGGCCTGCTGGCCTTCCTCTTCCTGTTCTCCTTCGCTACGGTTTTCG 480

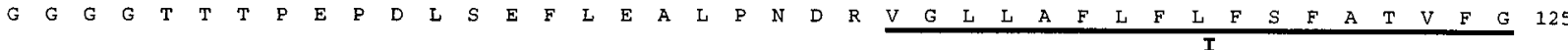

GCAACTCACTGGTCATCCTCGCCGTCATCCGGGAGCGGTACTTGCACACGGCCACCAACTACPTCA'CACCAGCCTGGCCGTGGCCGACTGCCTCGTGGGCCTGGTGGTCATGCCCTTCT 600

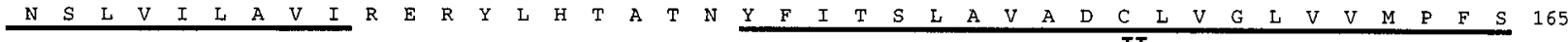
CAGCGCTCTACGAGGTGCTGGAGAACACGTGGTTCTTCGGCACGGACTGGTGCGACATCTGGCGGTCCCTGGACGTGCTCTTCAGCACAGCCTCCATACTGAATCTGTGCGTGATCTCAC 720

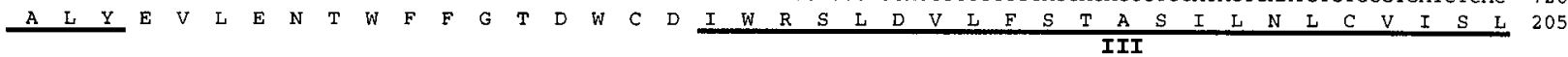
TCGACCGCTACTGGGCCATCACGGATCCCTTTAGCTATCCCATGAGGATGACGGTCAAGCGAGCGGCCGGTCTGATAGCCGCTGTATGGATCTGCTCCAGCGCCATTAGCTTTCCGGCCA 840

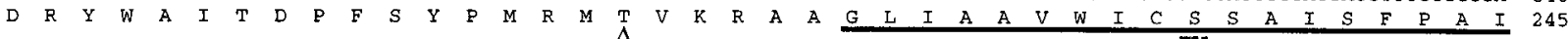
TTGTGTGGTGGCGAGCGGCGAGGGATGGCGAGATGCCCGCCTACAAGTGCACCTTCACCGAGCACCTGGGCTACCTAGTCTTCTCGTCGACGATATCCTTCIACCTGCCGCTTCTAGTGA 960

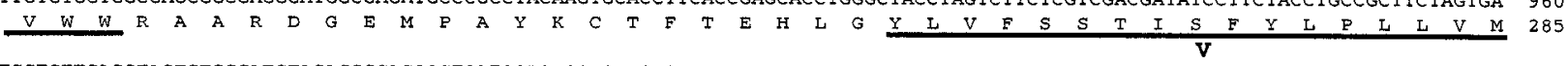
TGGTCPTCACCTACTGTCGCATCTACAGGGCAGCCGTCATCCAGACGAGATCTCTTAAGATTGGAACCAAGCAGGTGCTCATGGCCTCCGGGGAACTGCAGCTCACATTGCGTATTCATC 1080

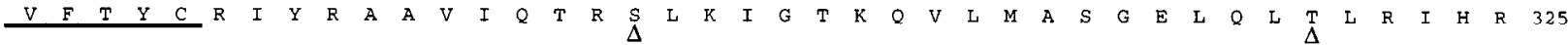
GTGGTGGCACTACGCGGGATCAGCAAAACCAGGTCTCCGGAGGAGGAGGTGGTGGAGGAGGAGGTGGCGGTGGCGGAGGATCTCTGAGCCACTCGCACTCCCATTCGCACCATCATCATC 1200

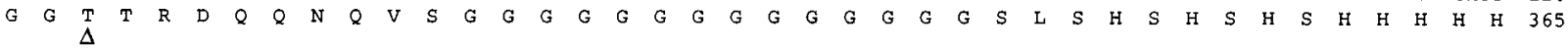
ACAATCACGGTGGTGGCACGACGACCTCCACGCCGGAGGAGCCGGATGATGAGCCGCTATCCGCTCTGCATAACAACGGACTGGCACGCCATCGGCACATGGGCAAGAACTTCTCGCTGT 1320

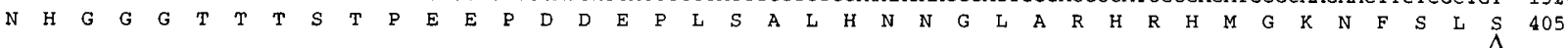
CCAGGAAACTGGCGAAGTTCGCCAAGGAGAAGAAGGCGGCCAAGACGCTGGGCATCGTGATGGGCGTGTTCATCATCTGCTGGCTGCCCTTCTTCGTGGTCAACCTGCTGTCCGGGTTCT 1440

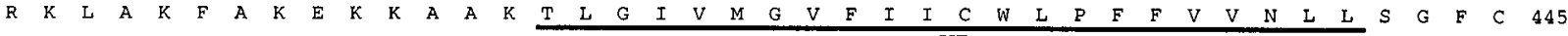
GCATCGAGTGCATCGAGCACGAGGAGATCGTCTCGGCAATCGTCACCTGGCTCGGCTGGATCAACTCCTGCATGAATCCTGTGATTTACGCCTGCTGGAGCAGGGACT"TTCGCAGGGCCT 1560

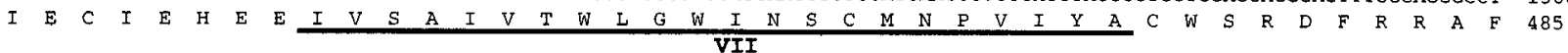
TTGTGCGTCTGCTGTGCATGTGCTGTCCACGCAAGATTCGCCGCAAGTACCAGCCCACGATGCGTTCCAAGTCGCAGAGA'I"LGCGACGCGGCGCTGCTACTCGACCTGCTCGCTGCACG 1680

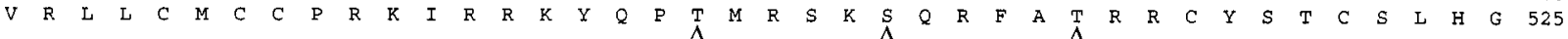
GCATTCAGCACGTGCGACACAACTCCTGCGAGCAGACCTACATATAGTTTAGCGTAGATTTAGTTGACAATGATTAagGCGCCGAGCCACGCCCCCTAGCGCCCTCCATTTGTCCGTAAG 1800 I $Q \begin{array}{lllllllllllllllll} & \mathrm{H} & \mathrm{V} & \mathrm{R} & \mathrm{H} & \mathrm{N} & \mathrm{S} & \mathrm{C} & \mathrm{E} & \boldsymbol{Q} & \mathrm{T} & \mathrm{Y} & \mathrm{I} & \text { * }\end{array}$

TCAATGGCAAGTGTCACGTGGCCGCTGCAATGGTGGCCGCCTCCACCTCCTTCGGCTACCACTCGGTGAACCAGATCGACCGGACGCTCATGTGACGGCAGCTGAGCAGTTGCAGCACCT 1920 GCAGCGGGGGCAGCAACTGCGGCGGATCACGGTCCGCCCATCACCAGCACCACTCCTCGGGCACGGCCACGCCCTCGTCCTCGCAGCGATCCTGCACTAGATGCCAGAGCTTCCACCGCC 2040 ACCACCACCGCTCCAGGCGCCGCAGCTCGGGGATGCAGATGCGCGGGGACTACAACTCCACCACGGCGGTGAACAGCGCTCTGGCCAAGACCATAGTCACCATCAGTGCTTCTCCGGTGG 2160 CGGCTGCCTCGGCCAGTTCGCTGCACCTGGGCGTCGGAGGACGTCCTTCCTCGGTGTCCACCCTGACAATCGCCTCGGTGCCGCCCACCTTGAGTGGCAGTGGCAGTCCAGGAGGCTCTG 2280 TGAGCGGGGCCACTACTCCGCTGGCACCCAGTCTCAAGGCCCTGACCCCGGGACCCTCCAACTCGTCGGGTCACCACGTGTCTITTCATGCCCATGACGGGCATGAAGCGGTTGCGCAGT 2400 CGAACGTCTCGCTGGGATCGACCAATGGAATCATCAGCACTGTGGCCGGAGCGGACACCACCTCGGCGCCCTTGCTGATCGACGCCAGCGAGGATCAGGTGCAGATGCGGAACCAACACC 2520 GAATCCTGGAGCAGTGCCAGAGTGTCCAGAGCCAAATAACTACGCTGGGCGACGTGGAGGACGACGACGAGGAGGTCAGCGACAGTGAGAGCGAGAGCATCGGACTCGCCCTGGTGGTGA 2640 CCACGCCTCAACTGGAGAGCCAGCCCGTGGAGGCATCGAGTTCCTCCAGCTCCTCGGTCAGGTAAACTCAGCAACAGAACCACGAAAACAAGCCCAGACATTAGCTTTAAGATTCAACCA 2760 TATACATATGTGTGTTTATCAGAAGCGGTGGTCGATGGAAAGGCAATACTTTGGACAGTTCTAAGCCAGTCAGAATTCACTTTGTTGCCTATTGATTATTTTACTAGCTCTTCAGGTTTC 2880 AATAAGGATATGAACTGAATTTTATTATCATCCCCCCAGCAAAGATTTGTGTATGTATGTATGTTATTTTTACCTTCAAGCGAATCAATATAGCTCAATCCGAATTGCAATTGGCTTAGA 3000 GGTGTCCATTGAGTTTCGCCAGCCCATTGGTCGACCCATTCGAAGTGTGTACATAGCAATCTAGACTCGCCTAGCCACTCATTAGCTTATCGATCGGTGATAGAACACTATGCAACAGAA 3120 AATCCTCCCTATATCAACACCCAAAAACACGGGGTTGCAGTTGCAGTTGCAGGCGGTAGTTGCATAGTGGGATTAGTGTAACTGTTAGCTCTCATATCTTAGATCTTCCATTATGTAGTT 3240 GTTCGTTCCGTTTCGTTCCGTTCCGTTCTGTAAATGTTTCAAACGTCTAGCAATTGAATTCAAAAAGCTACGTCTTCAACCTGTCCAAGTACCTGACTCTCTGAAATCCAAGAAGATACT 3360 GTGCATGTATATAGCTTAACTTTGACTCCTCTGTCGCTCAAAACTAGCTTTATGTTACTCGAAACTCGCTTGTTCGTTCGTTATCAACTGAAATTCTACGGGTGCAATATGAATTTATAC 3480 CAACTTAAGGACTCGAACAATCAGGCAAACAGGCTTCAAGACCAGTTCCCAGTCGTAGGAGATCCCAGGTACAAACTCATAATCACTGCAATTGTTGGCTAGCTTAATTAGCCCATCCTC 3600 CATTACGTTCTTTGGACTACATATATTACCAATATAGGCATATGGAATAGGGTGAATTTTAATTGTACTTGTGAGACAGCCGAAAGTTAGGAAATCCGGCAGCTTTAATGAATTAATCCC 3720 TCAAAAGGCTCGCCCATCCACTTCTGTACCACTCTACATGTATGCTTATGATGGCTAAGCTCCTCCGATTCCGATTTTGCAATAATTAATGTGTGCAATTAGGATTGATTGCCCCGCCCC 3840 CACAAGGTCGGCGAATAAATCGAGTAGAAGAATGGGGCTCTAATGCGGGAAAAACTAATAACAATGGCGAGACGTCAGTTTAATGGATGAGTAGGAAGAAGCCATGGCAAAATGTTGCTC 3960 ATTGTTTTCAAAAAACAAACAAAGCGAAATGGATGGTCCAAGG

B

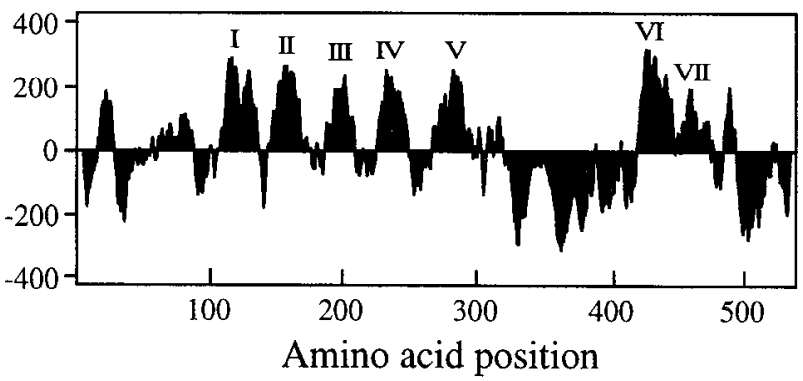

Figure 1. The DopR99B sequence. A, Nucleotide sequence and deduced amino acid sequence of the Drosophila dopamine receptor DopR99B. In-frame stop codons are indicated by asterisks. The sequence of a potential ribosome binding site is boxed. The seven transmembrane domains are underlined and numbered. Potential PKC phosphorylation sites are indicated by $\Delta$. Potential $\mathrm{N}$-glycosylation sites are marked by $\bullet . B$, Hydrophobicity plot of the deduced DopR99B amino acid sequence. Regions above the line are hydrophobic. Transmembrane domains are numbered. The hydropathy plot was done using the method of Kyte and Doolittle (1982) and the Geneworks software (Intelligenetics). The Genbank accession number for DopR99B is U34383. 
Pathway Accession \#

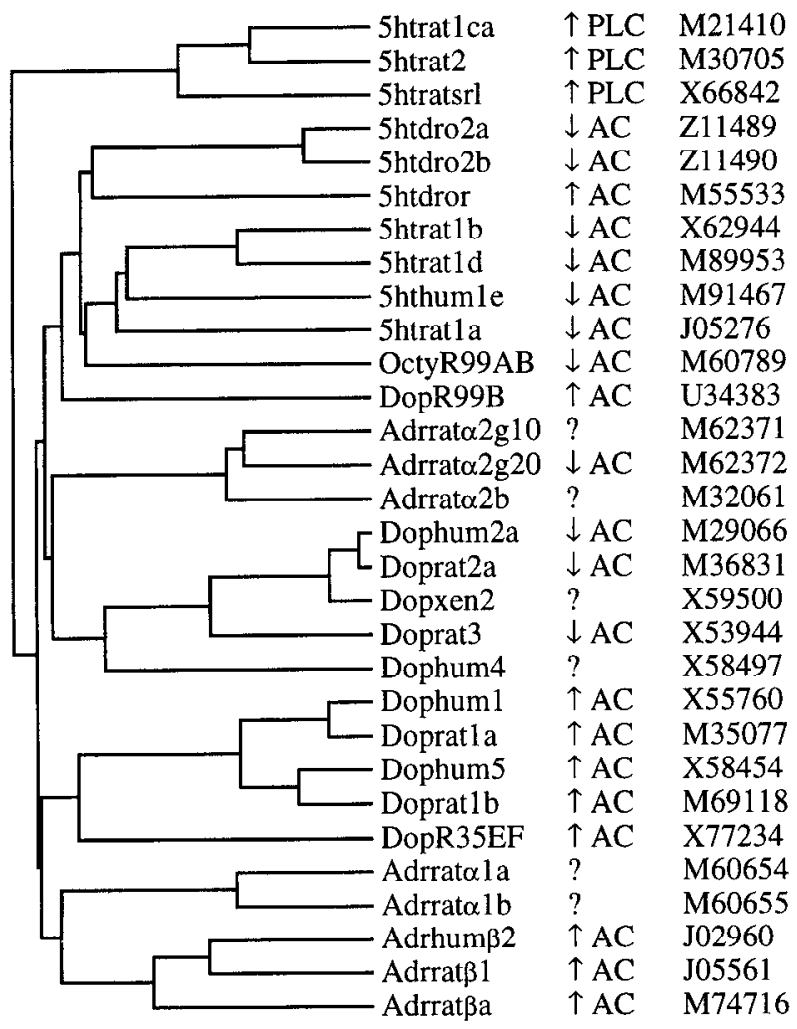

Figure 2. Structural relationship of DopR99B with other G-proteincoupled receptors. Scquence alignment was done with the PILEUP program of the Wisconsin Genetic Computer Group (GCG) software (Devereux et al., 1984) using the hydrophobic cores of each receptor listed. The hydrophobic core was defined as the region between and including transmembrane domains I and $\mathrm{V}$ plus the region between and including transmembrane domains VI and VII. The lengths of the horizontal lines are inversely proportional to the percentages of sequence similarity between receptors or groups of receptors. In the receptor names listed, the first three to four letters refer to the general receptor type: $A d r$, adrenergic; Dop, dopamine; $5 h t$, serotonin; Octy, octopamine/tyramine. The next letters in the name refer to the species: dro, Drosophila; hum, human; rat, rat; xen, Xenopus. The exceptions to this nomenclature are three Drosophila receptors (DopR35EF, DopR99B, OctyR99AB). For these, the type name is followed by $R$ (receptor) and then the salivary gland chromosome map position. Pathway refers to the sccond-messenger coupling reported in the literature for each receptor: $P L C$, phospholipase $\mathrm{C} ; A C$, adenylyl cyclase. An upward arrow indicates stimulation of the indicated secondmessenger system, and a downward arrow indicates inhibition. Accession \# refers to the Genbank database locator number.

all cloned G-protein-coupled receptors. A reverse primer sequence (OPS4) was from the conserved middle region of transmembrane domain VI of OctyR $99 A B$ cDNA (encoding amino acids FVICWLP). Genomic DNA was used as the template to avoid assumptions concerning the time- and tissue-specific expression of receptors.

Using the OPS3 and OPS4 PCR primers, five fragments (1.7, $1.0,0.68,0.60$, and $0.46 \mathrm{~kb}$ ) were amplified from Drosophila genomic DNA. Direct sequencing of the PCR products revealed that the $1.7 \mathrm{~kb}$ fragment is the genomic equivalent of OctyR $99 A B$ with a $0.7 \mathrm{~kb}$ intron in the region encoding cytoplasmic loop 3 . The $0.68 \mathrm{~kb}$ fragment had high sequence similarity to $O c t y R 99 A B$ and other G-protein-coupled receptors in the transmembrane domains, but was different in cytoplasmic loop 3. These data suggested that this $0.68 \mathrm{~kb}$ fragment encodes part of a novel
G-protein-coupled receptor gene in Drosophila. Using this $0.68 \mathrm{~kb}$ PCR fragment as a probe, four overlapping cDNA clones were isolated from an adult head cDNA library. The clone with the longest insert $(4 \mathrm{~kb})$ was completely sequenced and has been designated DopR99B.

\section{Structural features of the DopR99B cDNA sequence}

The $4 \mathrm{~kb}$ cDNA insert contains an open reading frame encoding 538 amino acids with a predicted molecular mass of $59.5 \mathrm{kDa}$ (Fig. $1 A$ ). The open reading frame is defined by the first in-frame ATG that is preceded by an in-frame stop codon. Although the flanking sequence preceding this ATG ( -4 to -1 , TGCA) does not match well with the Drosophila consensus sequence for a translation start site [C/A A A A/C (Cavener, 1987)], a potential ribosome-binding site around this ATG was identified (Fig. 1A). A comparison of the cDNA sequence in the regions used for the original PCR primers shows that in the forward primer region there are 4 base mismatches concentrated in the first 7 nucleotides from the $5^{\prime}$ end. The reverse primer had only 1 base mismatch in the fourth base position from the $3^{\prime}$ end. The robust amplification of the 0.68 $\mathrm{kb}$ product indicates that these mismatches were all tolerated at the initial annealing temperature of $33^{\circ} \mathrm{C}$.

\section{Sequence comparison with other G-protein-coupled receptors}

The deduced amino acid sequence for DopR99B shows many standard characteristics of the G-protein-coupled receptor gene family. The hydropathy plot (Fig. $1 B$ ) reveals the 7 transmembrane domains diagnostic of all members of this group of receptors (Probst et al., 1992). At the cytoplasmic end of transmembrane domain III is the highly conserved DRY sequence. This amino acid triplet is thought to be important in G-protein coupling (Dixon et al., 1987; Fraser et al., 1988). Single cysteine residues (at 182 and 261) in extracellular loops 1 and 2, respectively, are also conserved. These residues form a disulfide bond that stabilizes the functional receptor structure (Dixon et al., 1987; Karnik et al., 1988; Fraser, 1989). Two aspartate residues in TM II and TM III that are conserved in all catecholamine receptors are also conserved in DopR99B (D154 and D189). These two aspartates are thought to play a direct role in binding the amine groups on catecholamines (Strader et al., 1988). The three serine residues in TM V that are postulated to interact with the catecholamine ring hydroxyl groups (Strader et al., 1989; Pollock et al., 1992) are also conserved in DopR99B (S273, S274, S277). Thus, this new receptor has appropriately placed amino acid side chains for binding catecholamines.

There are other, more general structural motifs that are found in this Drosophila receptor as well as in other G-protein-coupled receptors. For example, mammalian dopamine receptors typically have one to four $\mathrm{N}$-linked glycosylation sites in their extracellular domains (Jackson and Westlind-Danielsson, 1994). This Drosophila receptor has four potential $\mathrm{N}$-linked glycosylation sites in the amino terminus (positions 5, 31, 47, and 68). This region is likely to be an extracellular domain. All G-protein-coupled receptors have protein kinase $\mathrm{C}$ sites in cytoplasmic loop 3 (between TM V and VI) and in the C-terminal tail, but the exact positions of these sites are not strictly conserved. This newly cloned Drosophila receptor has eight potential protein kinase $\mathrm{C}$ phosphorylation sites in cytoplasmic loop 2 (position 222), cytoplasmic loop 3 (positions 302, 320, 328, and 405), and in the $C$ terminus (positions 504, 509, and 514). Finally, many G-protein-coupled receptors undergo a post-translational palmitoylation at a conserved 
cysteine residue in the C-terminal tail (Gingrich and Caron, 1993). This modification serves to anchor the tail to the internal face of the plasma membrane, creating a fourth cytoplasmic loop. The Drosophila receptor has several cysteines that could serve this function (at 490, 492, 493, 517, 521, and 534). The conserved structural motifs, along with the fact that this gene product has, overail, a high sequence similarity with other G-protein-coupled receptors, suggest that it encodes a novel G-protein-coupled receptor in Drosophila.

Comparison of the predicted hydrophobic core region of the DopR99B deduced amino acid sequence revealed significant sequence similarity with vertebrate and invertebrate dopamine receptors (41-47\% identity), serotonin receptors ( $40-47 \%$ identity), $\alpha 1$ - and $\beta$-adrenergic receptors ( $46-48 \%$ identity), as well as the Drosophila octopamine/tyramine receptor from which the primers were derived ( $47 \%$ identity). Detailed sequence comparison of either the hydrophobic core region or the full-length deduced amino acid sequence showed that the DopR99B receptor clearly belonged to the biogenic amine class of receptors, but it was not possible to predict its receptor type based on sequence comparisons alone. The dendrogram in Figure 2 shows that DopR99B did not fall clearly within one of the biogenic amine receptor groups, although a previously described (Gotzes et al., 1994; Sugamori et al., 1995) Drosophila dopamine receptor (DopR35EF) consistently grouped with the vertebrate D1-like dopamine receptors. To define the DopR99B receptor-type pharmacologically, we expressed it in Xenopus oocytes.

\section{Expression studies in Xenopus oocytes}

Xenopus oocytes translate exogenous mRNAs encoding neurotransmitter receptors and incorporate the receptor proteins into their cell membranes (Sumikawa et al., 1981; Barnard et al., 1982). To define which ligands activate the DopR99B receptor, we expressed its cRNA in Xenopus oocytes and tested the ability of a range of biogenic amines to initiate responses. The application of dopamine initiated transient inward current responses in injected oocytes (Fig. 3A). Uninjected, control oocytes showed no responses (data not shown). The responses have a reversal potential of $-21.7 \pm 2.9 \mathrm{mV}(n=3)$ estimated from current-voltage $(I-V)$ plots, consistent with their mediation via the activation of the endogenous, inward calcium-dependent chloride current of the oocyte. This inward current is presumably generated by the same mechanism originally reported by Masu et al. (1987) after stimulation of another G-protein-coupled receptor (the bovine substance-K receptor) expressed in oocytes; i.e., receptormediated activation of phospholipase $\mathrm{C}$ increases PI hydrolysis and stimulates release of intracellular calcium which, in turn, activates the endogenous calcium-dependent chloride current of the oocyte.

Dose-response curves (Fig. 3B) indicate that the threshold response to dopamine occurred in the region of $1 \mathrm{~nm}$, whereas the maximal response occurred at $1 \mu \mathrm{M}$. Exposure of injected oocytes to concentrations of dopamine $>1 \mu \mathrm{M}$ consistently produced smaller responses (Fig. $3 A, B$ ). Figure $3 B$ also shows that the catecholamines norepinephrine and epinephrine induce inward currents in injected oocytes. However, these catecholamines are less effective than dopamine. The injected oocytes also showed inward currents when exposed to tyramine (Fig. $3 B$ ), but much higher concentrations were required and the average current response was smaller at the maximum concentration tested (100 $\mu \mathrm{M})$ than for the other amines. Oocytes showed no response to either DL-octopamine or 5-hydroxytryptamine at concentrations
A
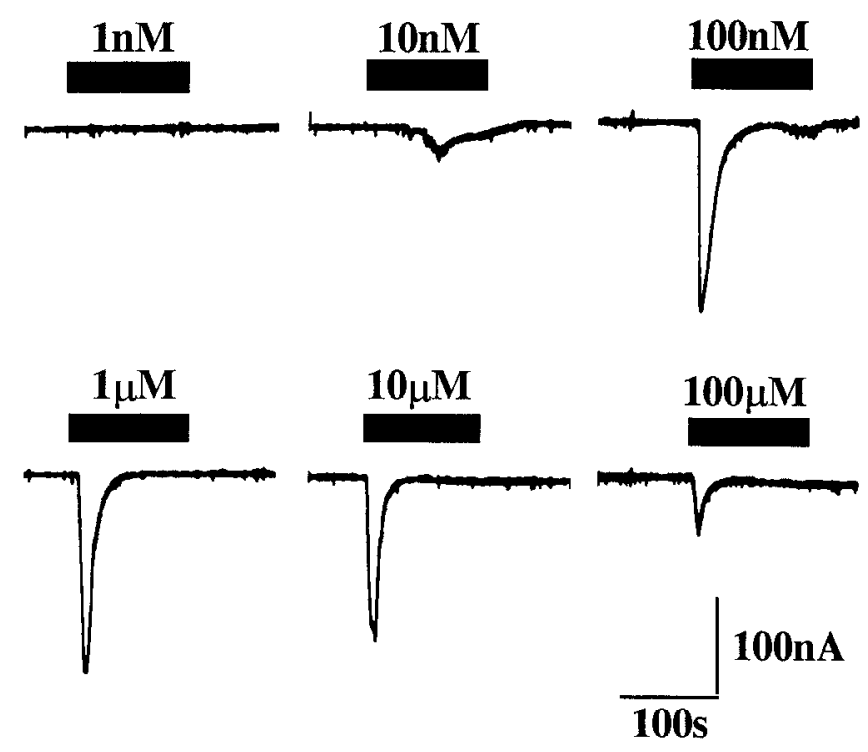

B

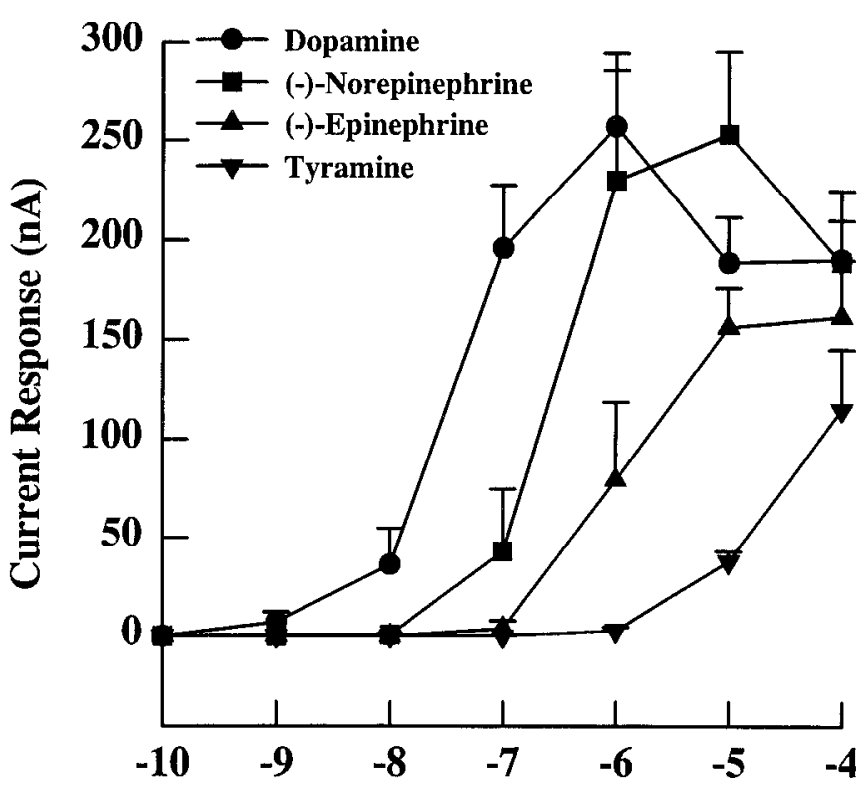

Log [Agonist] (M)

Figure 3. Inward current response after agonist stimulation mediated by the DopR99B receptor expressed in Xenopus oocytes. Two minute pulses of agonists were given to Xenopus oocytes $3 \mathrm{~d}$ after the injection of DopR99B cRNA. $A$, Typical responses of a single oocyte to various concentrations of dopamine. $B$, Dose-response curves for dopamine, $(-)$-norepinephrine, $(-)$-epinephrine, and tyramine. The results (from at least 6 oocytes) are expressed as the mean peak inward current $\pm \mathrm{SE}$ initiated by each amine.

up to $100 \mu \mathrm{M}$. Taken together, these results suggest that the DopR99B cDNA clone encodes a Drosophila dopamine receptor.

To determine whether this Drosophila dopamine receptor falls into the D1-like or D2-like pharmacological category, the ability of antagonists $(10 \mu \mathrm{M})$ to block the responses to $1 \mu \mathrm{M}$ dopamine 
Table 1. Effects of agonists and antagonists on inward currents in Xenopus oocytes expressing the Drosophila DopR99B receptor

A

\begin{tabular}{lcll}
\hline Antagonists $(10 \mu \mathrm{M})$ & $\begin{array}{l}\% \text { of Response to } \\
1 \mu \mathrm{M} \text { dopamine }\end{array}$ & $\begin{array}{l}\text { Receptor-type } \\
\text { specificity }\end{array}$ \\
\hline Flupenthixol & $3.9 \pm 1.6 \%$ & $(n=5)$ & D1/D2-like \\
$R(+)$ SCH23390 & $34.2 \pm 8.9 \%$ & $(n=6)$ & D1/D5 \\
$S(-)$-sulpiride & $56.8 \pm 16.1 \%$ & $(n=5)$ & D2-like \\
Spiperone & $63.0 \pm 9.2 \%$ & $(n=7)$ & D2-like \\
(+)Butaclamol & $66.7 \pm 4.5 \%$ & $(n=6)$ & D2/D1-like \\
Phentolamine & $71.6 \pm 7.1 \%$ & $(n=6)$ & $\alpha$-Adrenergic \\
DL-Propranolol & $89.6 \pm 5.9 \%$ & $(n=7)$ & $\beta$-Adrenergic \\
$S(-)$-cticlopride & $103.2 \pm 10.9 \%$ & $(n=4)$ & D2-like \\
Domperidone & $118.3 \pm 7.0 \%$ & $(n=3)$ & Peripheral D2
\end{tabular}

B

\begin{tabular}{|c|c|c|c|}
\hline \multirow{2}{*}{$\frac{\text { Agonists }(10 \mu \mathrm{M})}{( \pm)-6 \text {-Chloro-APB }}$} & \multicolumn{2}{|c|}{$\begin{array}{l}\% \text { of Response to } \\
1 \mu \mathrm{M} \text { dopamine }\end{array}$} & \multirow{2}{*}{$\begin{array}{l}\begin{array}{l}\text { Receptor-type } \\
\text { specificity }\end{array} \\
\text { Dl-like }\end{array}$} \\
\hline & $89.4 \pm 3.8 \%$ & $(n=6)$ & \\
\hline$R(+)$-6-bromo-APB & $73.3 \pm 9.1 \%$ & $(n=6)$ & DI-like \\
\hline ( \pm )-6-Chloro-PB & $19.6 \pm 7.7 \%$ & $(n=5)$ & D1-like \\
\hline Quinelorane & $11.3 \pm 3.0 \%$ & $(n=8)$ & D2-like \\
\hline$( \pm)$-Bromocriptine & $7.5 \pm 2.6 \%$ & $(n=5)$ & D2-like \\
\hline Quinpirole & $4.1 \pm 2.3 \%$ & $(n=6)$ & $\mathrm{D} 2 / \mathrm{D} 3$ \\
\hline$R(+)-\mathrm{SKF}-38393$ & $1.8 \pm 1.2 \%$ & $(n=6)$ & D1-like \\
\hline$( \pm)$-Isoproterenol & $1.3 \pm 0.9 \%$ & $(n=6)$ & $\beta$-Adrenergic \\
\hline PD-128,907 & 0 & $(n=6)$ & D3 \\
\hline$( \pm)$-PPHT & 0 & $(n=4)$ & D2-like \\
\hline
\end{tabular}

Inward currents were initiated by $2 \mathrm{~min}$ pulses of $1 \mu \mathrm{M}$ dopamine. The mean response to a 2 min control pulse of $1 \mu \mathrm{M}$ dopamine was $331.4 \pm 15.6 \mathrm{nA}(n=73)$. $A$, The size of the response to a dopamine pulse given in the presence of $10 \mu \mathrm{M}$ antagonist is expressed as a percentage $\pm \mathrm{SE}$ of the response to a control dopamine pulse given to the same oocyte. Antagonists alone did not initiate any currents.

B, Agonists were applied as 2 min pulses. The inward currents gencratcd are expressed as the percentage $\pm \mathrm{SE}$ of the response of the same oocyte to a control dopamine pulse.

in oocytes expressing the DopR99B receptor was determined (Table 1A). The rank order potency of the dopaminergic antagonists tested was: flupenthixol $>R(+)-\mathrm{SCH}-23390>S(-)$ sulpiride $>$ spiperone $>(+)$ butaclamol $>S(-)$ eticlopride $=$ domperidone. The D1-like receptor blockers were, in general,

Table 2. Effects of biogenic amines on cAMP levels in Xenopus oocytes expressing the Drosophila DopR99B receptor

\begin{tabular}{lllll} 
Agonist & $\begin{array}{l}\text { DopR99B } \\
\text { cRNA-injected }\end{array}$ & Uninjected & \\
\hline Basal & $0.82 \pm 0.05$ & $(n=9)$ & $0.87 \pm 0.08$ & $(n=10)$ \\
Dopamine & $1.46 \pm 0.10$ & $(n=10)$ & $0.77 \pm 0.09$ & $(n=10)$ \\
$(-)$-Epinephrine & $1.28 \pm 0.15$ & $(n=8)$ & $0.76 \pm 0.08$ & $(n=10)$ \\
(-)-Norepinephrine & $1.15 \pm 0.06$ & $(n=8)$ & $0.71 \pm 0.07$ & $(n=9)$ \\
Phenylethylamine & $0.86 \pm 0.09$ & $(n=10)$ & $0.69 \pm 0.10$ & $(n=10)$ \\
5-Hydroxytryptamine & $0.83 \pm 0.09$ & $(n=5)$ & $0.96 \pm 0.05$ & $(n=5)$ \\
DL-Octopamine & $0.78 \pm 0.07$ & $(n=10)$ & $0.69 \pm 0.08$ & $(n=10)$ \\
Phenylethanolamine & $0.76 \pm 0.06$ & $(n=10)$ & $0.89 \pm 0.06$ & $(n=10)$ \\
Tyramine & $0.71 \pm 0.08$ & $(n=10)$ & $0.71 \pm 0.09$ & $(n=9)$
\end{tabular}

cAMP levels were measured $5 \mathrm{~d}$ after cRNA injection. Before measurement, oocytes were preincubated for $30 \mathrm{~min}$ in $100 \mu \mathrm{M}$ IBMX and then exposed to $10 \mu \mathrm{M}$ biogenic amine for $30 \mathrm{~min}$ in the presence of $100 \mu \mathrm{M}$ IBMX. The results are expressed as the mean oocyte cAMP level (pmol/oocyte) $\pm \mathrm{SE}$.

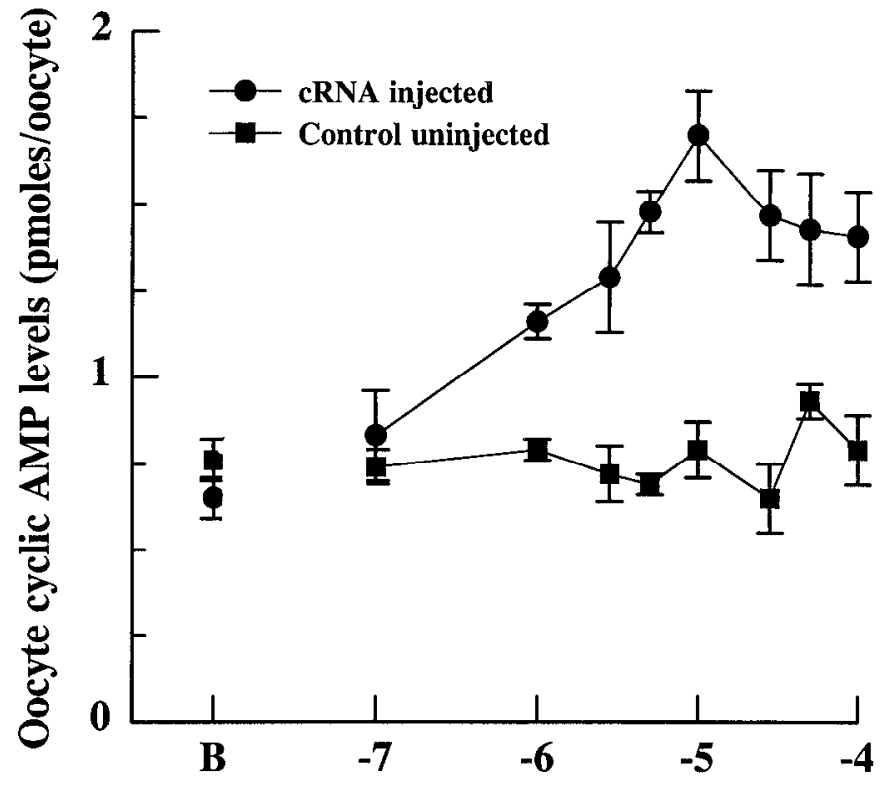

Log [Dopamine] (M)

Figure 4. Dose-response curves for increase in cAMP levels in oocytes expressing DopR99B. Five days after injection with Drosophila DopR99B receptor CRNA, injected and uninjected (control) oocytes were treated with the indicated dopamine concentrations for $30 \mathrm{~min}$ in the presence of $100 \mu \mathrm{M}$ IBMX after preincubation for $30 \mathrm{~min}$ in $100 \mu \mathrm{M}$ IBMX. The results are expressed as the mean oocyte cAMP level (pmol/oocyte) $\pm \mathrm{SE}$ $(n=5$ oocytes). $B$, Basal levels.

more effective than those with $\mathrm{D} 2$-like receptor specificity. The $\alpha$-adrenergic blocker phentolamine and the $\beta$-adrenergic blocker DL-propranolol were poor blockers, falling within the same range as the weaker D2-like receptor blockers. Thus, in terms of antagonist responses, the DopR99B receptor would be classed with the D1-like dopamine receptor group.

When a range of synthetic dopamine agonists specific for various vertebrate receptor subtypes was tested (Table 1B), both D1-like and D2-like agonists mimicked the dopamine responses in oocytes expressing the DopR99B receptor. However, with the exception of the relatively ineffective D1-like agonist SKF-38393, the D1-like agonists were more effective than the D2-like agonists. Thus, these pharmacological studies of the inward currents generated by dopamine application indicate that the receptor encoded by the DopR99B cDNA, again, has a pharmacological profile closer to D1-like dopamine receptors.

Another way to categorize receptors is in terms of the secondmessenger systems to which they couple. Therefore, we have also investigated second-messenger coupling for the Drosophila DopR99B receptor. This receptor, when expressed in Xenopus oocytes, appears to couple to multiple second-messenger systems. As described above, receptor activation initiates a calcium response. In addition, dopanine activation of the DopR99B receptor also increases cAMP levels in oocytes (Fig. 4). This response is mimicked by the application of epinephrine and norepinephrine to expressing oocytes, but not by phenylethylamine, 5-hydroxytryptamine, DLoctopamine, phenylethanolamine, or tyramine when these agonists were tested at a concentration of $10 \mu \mathrm{M}$ (Table 2). Stimulation of cAMP levels is characteristic of second-messenger coupling by D1like receptors, whereas inhibition of cAMP synthesis is characteristic of D2-like receptors (see Fig. 2). Therefore, in this respect, 


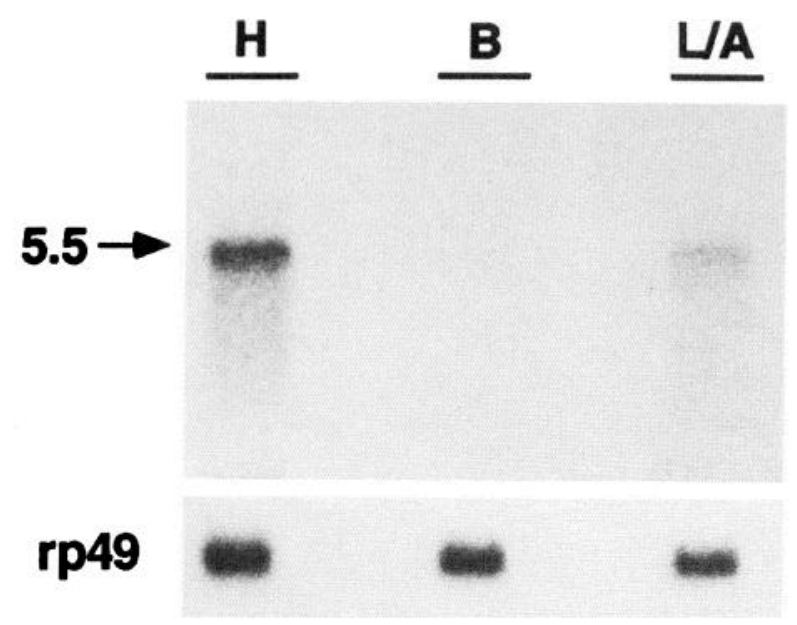

Figure 5. Northern blot analysis of DopR99B. A Northern blot of poly $(\mathrm{A})^{+}$RNA isolated from heads $(H)$, bodies $(B)$, and legs/antennae $(L / A)$ was probed with the ${ }^{32} \mathrm{P}$-labeled $0.68 \mathrm{~kb}$ PCR fragment. To control for mRNA recovery, the blot was reprobed with ribosomal protein cDNA $(r p 49)$, which is expressed throughout the organism (O'Connell and Robash, 1984).

DopR99B also resembles D1-like receptors. We have named this receptor DopR99B (for Dopamine Receptor from Drosophila mapping to $99 \mathrm{~B}$ to distinguish it from another Drosophila D1-like dopamine receptor (which we designate as DopR35EF) described previously (Gotzes et al., 1994; Sugamori et al., 1995).

\section{mRNA distribution and chromosomal localization of DopR99B}

To determine the distribution of the DopR99B transcript in different body parts, we did Northern blot analysis with poly $(\mathrm{A})^{+}$ RNA isolated from heads, bodies, and appendages (mostly legs and antennae). The blot was probed with the original $0.68 \mathrm{~kb}$ PCR fragment that contains the nonconserved cytoplasmic loop 3. As shown in Figure 5, a single band of $5.5 \mathrm{~kb}$ mRNA was detected predominantly in heads with a lighter signal in appendages. No expression was detected in bodies. This distribution is consistent with a role for these dopamine receptors in the central and peripheral nervous systems. The absence of major expression in bodies suggests that this receptor is not highly expressed in flight muscle.

To determine where DopR99B maps in the Drosophila genome, the $0.68 \mathrm{~kb}$ PCR fragment was biotinylated and hybridized to Drosophila salivary gland polytene chromosomes (Fig. 6). The probe hybridized to a single location on the right arm of chromosome 3 at 99B3-5. This location is close to, but distinct from, the Drosophila octopamine/tyramine receptor gene that maps to 99A10-B1 (Arakawa et al., 1990). The structural relationship between DopR99B and this Drosophila octopamine/tyramine receptor (OctyR99AB, Fig. 2) suggests that these receptors may be related by a local gene duplication followed by independent evolution.

\section{DISCUSSION}

The present study establishes, for the first time, the presence of multiple dopamine receptor types in insects. These receptors, which we have designated as DopR35EF [cloned in previous studies (Gotzes et al., 1994; Sugamori et al., 1995)] and DopR99B (present study), are similar in that both stimulate adenylyl cyclase when activated. Although both resemble the vertebrate D1-like

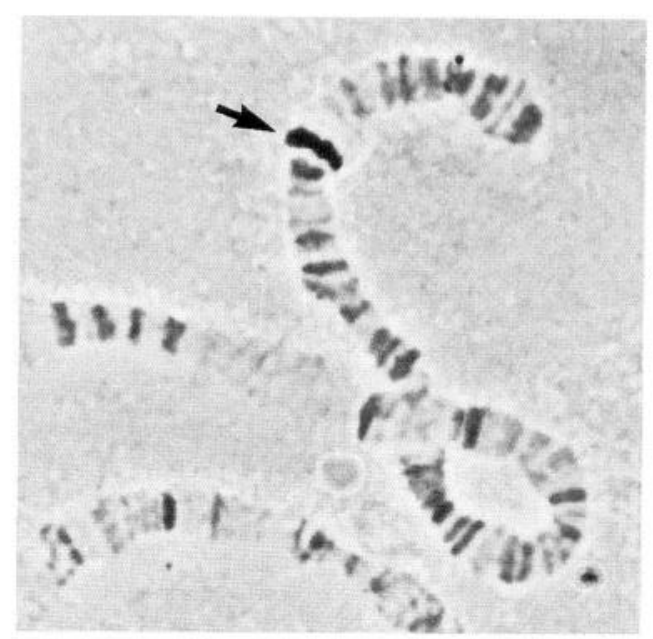

Figure 6. Chromosome localization of DopR99B. In situ hybridization to Drosophila salivary gland polytene chromosomes using the biotinylated $0.68 \mathrm{~kb}$ PCR fragment. The arrow indicates the site of hybridization at 99B3-5 on the right arm of chromosome 3.

dopamine receptor class, there are differences. For example, vertebrate D1-like receptors generally have long C-terminal tails ranging from 113 to 117 amino acids in length, whereas D2-like receptors have short tails in the range of 16-18 amino acids (Jackson and Westlind-Danielsson, 1994). The two Drosophila dopamine receptors have C-terminal tails that are intermediate in length (62 amino acids for DopR35EF and 64 for DopR99B).

Although the two Drosophila receptors resemble each other with respect to $\mathrm{C}$-terminal tail length, in overall sequence similarity DopR35EF is less similar to DopR99B (43\% sequence identity in the hydrophobic core region) than it is to the vertebrate D1-like class of dopamine receptors ( $46-48 \%$ identity). When dendrograms are constructed based on structural relatedness (e.g., Fig. 2), DopR35EF consistently falls into a group with vertebrate D1-like dopamine receptors regardless of whether the entire sequence or only the hydrophobic core is used for comparison. DopR99B does not group with the D1-like receptors, but instead shows almost equal sequence identity to a number of different biogenic amine receptor groups. This suggests that the dopamine receptor subtypes in Drosophila did not arise from each other but, rather, may represent convergent evolution from different precursors.

Although the Drosophila DopR99B receptor does not fall into the D1-like structural group, it does show pharmacological properties similar to D1-like receptors (Jackson and WestlindDanielsson, 1994; Seeman and VanTol, 1994) when expressed in Xenopus oocytes. Agonists and antagonists with D1-like selectivity are, in general, more effective than those with D2-like receptor selectivity. A comparison of our pharmacological data with the limited information on DopR35EF (Gotzes et al., 1994; Sugamori et al., 1995) suggests that these two Drosophila dopamine receptors differ in their pharmacological specificity. For example, the dopamine receptor agonist SKF-38393 is $30 \%$ as effective as dopamine on DopR35EF (Gotzes et al., 1994), but is almost inactive on DopR99B. With respect to antagonists, SCH-23390 is less effective than flupenthixol and butaclamol on DopR35EF, but is intermediate between flupenthixol and butaclamol on DopR99B.

Agonist stimulation of DopR99B activates adenylyl cyclase to increase cAMP levels and also generates a calcium signal presum- 
ably through stimulation of phospholipase C. Both of these responses have been reported for vertebrate D1-like receptors (Figure 2) (Mahan et al., 1990). In contrast, vertebrate D2-like receptors usually show opposite effects on these secondmessenger systems because they inhibit cAMP synthesis (Jackson and Westlind-Danielsson, 1994) and are associated with a decline in intracellular $\mathrm{Ca}^{2+}$ levels. Structural features, presumably in the second and third intracellular loops and in the C terminus, must underlie the ability of this Drosophila dopamine receptor to couple to two different second-messenger systems. Because the DopR $99 \mathrm{~B}$ receptor is structurally distinct from classical vertebrate dopamine receptors, the use of chimeras and the application of in vitro mutagenesis may produce novel insights into how dopamine interacts with this receptor and how this interaction results in the stimulation of different systems.

Our results leave unanswered the question of whether Drosophila has a D2-like dopamine receptor homolog. Dopamine and the enzymes involved in its synthesis are widely distributed in the insect nervous system (Klemm, 1976; Evans, 1980; Livingstone and Tempel, 1983; Brown and Nestler, 1985; Budnik and White, 1987). Previous studies demonstrating the presence of dopaminesensitive adenylyl cyclases in insect nervous tissue (Nathanson and Greengard, 1973; Bodnaryk, 1979; Uzzan and Dudai, 1982; Orr et al., 1987) and salivary glands (House and Ginsborg, 1979; LafonCazal and Bockaert, 1984; Evans and Green, 1990a,b; Ali and Orchard, 1994), together with radioligand binding studies on cockroach brains (Notman and Downer, 1987), suggested the presence of D1-like dopamine receptors in insects. These D1-like receptor responses could correspond to either the DopR99B receptor described in this report or the DopR35EF receptor (Gotzes et al., 1994; Sugamori et al., 1995) or both. There are no reports yet of D2-like dopamine receptor activity in insects, but this is not a well studied area. None of the other PCR amplification products found in our search for new receptor types in Drosophila encode additional dopamine receptors, although at least one product (the $0.60 \mathrm{~kb}$ fragment) represents another G-protein-coupled receptor (G. Feng, R. Venard, and L. M. Hall, unpublished results). Thus, a modification of our cloning strategy will be necessary to search for additional dopamine receptor cDNAs in Drosophila.

In insects, the dense innervation of the mushroom bodies by dopamine-immunoreactive neurons (Budnik and White, 1988; Schafer and Rehder, 1989: Nassel and Elkes, 1992), together with studics on behavioral mutants of Drosophila (Tempel et al., 1984; Buchner, 1991), has suggested roles for dopamine in both memory and learning, and in neuronal development. Analysis of the Drosophila mutant $D d c$, which is deficient in dopa decarboxylase (therefore lacking dopamine and serotonin), reveals learning deficits (Tempel et al., 1984) and an abnormal pattern of neuronal arborization (Budnik et al., 1989) that can be partially rescued by feeding flies dopamine, but not serotonin. These studies suggest possible roles for cloned dopamine receptors from Drosophila.

Our work, in conjunction with that of others (Gotzes et al., 1994; Suganori et al., 1995), establishes that there are at least two genetically distinct dopamine receptors in Drosophila that both stimulate adenylyl cyclase when activated. The DopR99B receptor is also capable of generating a calcium signal. Are either of these receptors involved in the signal transduction role that dopamine plays in learning and memory? Because the DopR35EF receptors are preferentially expressed in the optic lobes (Gotzes et al., 1994), they are unlikely to play a role in learning and memory that involves mushroom body-mediated functions. In contrast,
DopR99B is good candidate for dopaminergic modulation of learning and memory because this receptor is expressed preferentially in mushroom bodies ( $\mathrm{K}$. Han and R. Davis, personal communication). Genetic studies aimed at identifying dopamine receptor mutations in Drosophila will be useful in defining their physiological and behavioral roles.

\section{REFERENCES}

Ali DW, Orchard I (1994) Characterization of dopamine and serotonin receptors on the salivary glands of the locust, Locusta migratoria. Biog Amines 10:195-212

Arakawa S, Gocayne JD, McCombie WR, Urquhart DA, Hall LM, Fraser CM, Venter JC (1990) Cloning, localization, and permanent expression of a Drosophila octopamine receptor. Neuron 4:343-354.

Barnard EA, Miledi R, Sumikawa K (1982) Translation of exogenous messenger RNA coding for nicotinic acetylcholine receptors produces functional receptors in Xenopus oocytes. Proc $\mathrm{R}$ Soc Lond [Biol] 215:241-246

Bodnaryk RP (1979) Identification of specific dopamine- and octopamine-sensitive adenylate cyclases in the brain of Mamestra configurata Wik. Insect Biochem 9:155-162.

Brown CS, Nestler C (1985) Catecholamines and indolalkylamines. In: Comprehensive insect physiology, biochemistry and pharmacology, Vol 11 (Kerkut GA, Gilbert LI, eds), pp 436-497. Oxford: Pcrgamon.

Budnik V, White K (1987) Genetic dissection of dopamine and serotonin synthesis in the nervous system of Drosophila melanogaster. J Neurogenet 4:309-314

Budnik V, White K (1988) Catecholamine-containing neurons in Drosophila melanogaster distribution and development. J Comp Neurol 268:400-413

Budnik V, Wu C-F, White K (1989) Altered branching of serotonincontaining neurons in Drosophila mutants unable to synthesize serotonin and dopamine. J Neurosci 9:2866-2877.

Buchner E (1991) Genes expressed in the adult brain of Drosophila and effects of their mutations on behavior: a survey of transmitter- and second messenger-related genes. J Neurogenet 7:153-192.

Cavener DR (1987) Comparison of the consensus sequence flanking translational start sites in Drosophila and vertebrates. Nucleic Acids Res $15: 1353-1361$.

Civelli O, Bunzow JR, Grandy DK (1993) Molecular diversity of the dopamine receptors. Annu Rev Pharmacol Toxicol 33:281-307.

Devereux J, Haeberli P, Smithies O (1984) A comprehensive set of sequence analysis programs for the VAX. Nucleic Acids Res $12: 387-395$

Dixon RAF, Sigal IS, Candelore MR, Register RB, Scattergood W, Rands E, Strader CD (1987) Structural features required for ligand binding to the $\beta$-adrenergic receptor. EMBO J 6:3269-3275.

Engels WR, Preston CR, Thompson P, Eggleston WB (1985) In situ hybridization to Drosophila salivary chromosomes with biotinylated DNA probes and alkaline phosphatase. Focus 8:6-8.

Evans PD (1980) Biogenic amines in the insect nervous system. Adv Insect Physiol 15:317-473.

Evans AM, Green KL (1990a) The action of dopamine receptor antagonists on the secretory response of the cockroach salivary gland in vitro. Comp Biochem Physiol 97C:283-286.

Evans AM, Green KL (1990b) Characterization of the dopamine receptor mediating the hyperpolarization of cockroach salivary gland acinar cells in vitro. Br J Pharmacol 101:103-108.

Feng G, Deák P, Kasbekar DP, Gil DW, Hall LM (1995) Cytogenetic and molecular localization of tipE: a gene affecting sodium channels in Drosophila melanogaster. Genetics 139:1679-1688.

Fraser CM (1989) Site-directed mutagenesis of $\beta$-adrenergic receptors: identification of conserved cysteine residues that independently affect ligand binding and receptor activation. J Biol Chem 264:9266-9270.

Fraser CM, Chung FZ, Wang CD, Venter JC (1988) Site-directed mutagenesis of human $\beta$-adrenergic receptors: substitution of aspartic acid-130 by asparagine produces a receptor with high-affinity agonist binding that is uncoupled from adenylate cyclase. Proc Natl Acad Sci USA 85:5478-5482.

Gingrich JA, Caron MG (1993) Recent advances in the molecular biology of dopamine receptors. Annu Rev Neurosci 16:299-321.

Goldstein M, Deutch AY (1992) Dopaminergic mechanisms in the pathogenesis of schizophrenia. FASEB J 6:2413-2421. 
Gotzes F, Balfanz S, Baumann A (1994) Primary structure and functional characterization of a Drosophila dopamine receptor with high homology to human $\mathrm{D}_{1 / 5}$ receptors. Receptors Channels 2:131-141.

Hall H (1994) Dopamine receptors: radioligands for pharmacological and biochemical characterization. In: Dopamine receptors and transporters (Niznik HB, ed), pp 3-35. New York: Marcel Dekker.

Henikoff S (1987) Unidirectional digestion with exonuclease III in DNA sequence analysis. Methods Enzymol 155:156-165.

House CR, Ginsborg BL (1979) Pharmacology of cockroach salivary secretion. Comp Biochem Physiol 63C:1-6.

Itoh N, Salvaterra P, Itakura K (1985) Construction of an adult Drosophila head cDNA expression library with lambda gt11. Dros Inform Serv 61:89.

Jackson DM, Westlind-Danielsson A (1994) Dopamine receptors: molecular biology, biochemistry and behavioural aspects. J Pharmacol Exp Ther 64:291-369.

Jowett T (1986) Preparation of nucleic acids. In: Drosophila: a practical approach (Roberts DB, ed), Washington, DC: IRL.

Karnik SS, Sakmar TP, Chen HB, Khorana HG (1988) Cysteine residues 110 and 187 are essential for the formation of the correct structure in bovine rhodopsin. Proc Natl Acad Sci USA 85:8459-8463.

Kebabian JW, Calne DB (1979) Multiple receptors for dopamine. Nature 277:93-96.

Klemm N (1976) Histochemistry of putative transmitter substances in the insect brain. Prog Neurobiol 7:99-169.

Kyte J, Doolittle RF (1982) A simple method for displaying the hydropathic character of a protein. J Mol Biol 157:105-132.

Lafon-Cazal M, Bockaert J (1984) Pharmacological characterization of dopamine-sensitive adenylate cyclase in the salivary glands of Locusta migratoria L. Insect Biochem 11:541-545.

Levinson DF (1991) Pharmacological treatment of schizophrenia. Clin Ther 13:326-352.

Livingstone MS, Tenpel BL (1983) Genetic dissection of monoamine neurotransmitter synthesis in Drosophila. Nature 303:67-70.

Mahan LC, Burch RM, Monsma Jr FJ, Sibley DR (1990) Expression of striatal $D_{1}$ dopamine receptors coupled to inositol phosphate production and $\mathrm{Ca}^{2+}$ mobilization in Xenopus oocytes. Proc Natl Acad Sci USA 87:2196-2200.

Masu Y, Nakayama K, Tamaki H, Harada Y, Kuno M, and Nakanishi S (1987) cDNA cloning of bovine substance-K receptor through oocyte expression system. Nature 329:836-838.

Nassel DR, Elkes K (1992) Aminergic neurons in the brain of blowflies and Drosophila: dopamine- and tyrosine hydroxylase-immunoreactive neurons and their relationship with putative histaminergic neurons. Cell Tissue Res 267:147-167.

Nathanson JA, Greengard P (1973) Octopamine-sensitive adenylate cyclase: evidence for a biological role of octopamine in nervous tissue. Science 180:308-310.

Notman HJ, Downer RGH (1987) Binding of $\left[{ }^{3} \mathrm{H}\right]$ pifluthixol, a dopamine antagonist, in the brain of the American cockroach, Periplaneta americana. Insect Biochem 17:587-590.

O'Connell P, Rosbash M (1984) Sequence, structure, and codon preference of the Drosophila ribosomal protein 49 gene. Nucleic Acids Res 12:5495-5513.

Onai T, Fit7Gerald MG, Arakawa S, Gocayne JD, Urquhart DA, Hall LM, Fraser CM, McCombie WR, Venter JC (1989) Cloning, sequence analysis and chromosome localization of a Drosophila muscarinic acetylcholine receptor. FEBS Lett 255:219-225.

Orr GL, Gole JWD, Notman HJ, Downer RGH (1987) Pharmacological characterization of the dopamine-sensitive adenylate cyclase in cockroach brain: evidence for a distinct dopamine receptor. Life Sci 41:2705-2715.

Pollock NJ, Manelli AM, Hutchins CW, Steffey ME, MacKenzie RG, Frail DE (1992) Serine mutations in transmembrane- $V$ of the dopamine D1-receptor affect ligand interactions and receptor activation. J Biol Chem 267:17780-17786.
Probst WC, Snyder LA, Schuster DI, Brosius J, Sealfon SC (1992) Sequence alignment of the G-protein coupled receptor supcrfamily. DNA Cell Biol 11:1-20.

Sambrook J, Fritsch EF, Maniatis T (1989) Molecular cloning: a laboratory manual, 2nd ed. Cold Spring Harbor, NY: Cold Spring Harbor Laboratory.

Saudou F, Boschert U, Amlaiky N, Plassat J-L, Hen R (1992) A family of Drosophila serotonin receptors with distinct intracellular signalling properties and expression patterns. EMBO J 11:7-17.

Schafer S, Rehder V (1989) Dopamine-like immunoreactivity in the brain and suboesophageal ganglion of the honey bee. J Comp Neurol $280: 43-58$.

Schmidt-Nielsen BK, Gepner JI, Teng NNH, Hall LM (1977) Characterization of an $\alpha$-bungarotoxin binding component from Drosophila mela nogaster. J Neurochem 29:1013-1029.

Seeman P, VanTol HHM (1994) Dopamine receptor pharmacology. Trends Pharmacol Sci 15:264-270.

Seeman P, Ulpian C, Bergeron C, Riederer P, Jellinger K, Gabriel E, Reynolds GP, Tourtellotte WW (1984) Bimodal distribution of dopamine receptor densities in brains of schizophrenics. Science 225:728-730

Sonetti D, Biondi C, Ferretti ME, Portolan A, Brunelli M (1987) Effects of serotonin, dopamine and prostaglandin-E2 on adenylate-cyclase activity and cyclic AMP levels in different ganglia of the fresh water snail Planorbis corneus L. Neurochem Int 11:119-126.

Strader CD, Sigal IS, Candelore MR, Rands E, Hill WS, Dixon RAF (1988) Conserved aspartic acid residue-79 and residue-113 of the $\beta$-adrenergic receptor have different roles in receptor function. $\mathbf{J}$ Biol Chem 263:10267-10271.

Strader CD, Candelore MR, Hill WS, Sigal IS, Dixon RAF (1989) Identification of two serine residues involved in agonist activation of the $\beta$-adrenergic receptor. J Biol Chem 264:13572-13578.

Sugamori KS, Demchyshyn LL, McConkey F, Forte MA, Niznik HB (1995) A primordial dopamine D1-like adenylate cyclase-linked receptor from Drosophila melanogaster displaying poor affinity for benzazepines. FEBS Lett 362:131-138.

Sumikawa K, Houghton M, Fmtage JS, Richards BM, Barnard EA (1981) Active multi-subunit $\mathrm{ACh}$ receptor assembled by translation of heterologous mRNA in Xenopus oocytes. Nature 292:862-864.

Tcmpel BL, Livingstone MS, Quinn WG (1984) Mutations in the dopa decarboxylase gene affect learning in Drosophila. Proc Natl Acad Sci USA 81:3577-3581.

Uzzan A, Dudai Y (1982) Aminergic receptors in Drosophila melanogaster: responsiveness of adenylate cyclase to putative neurotransmitters. J Neurochem 38:1542-1550.

Van Renterghem C, Bilbe G, Moss S, Smart TG, Constanti A, Brown DA Barnard EA (1987) GABA receptors induced in Xenopus oocytes by chick brain messenger RNA: evaluation of TBPS as a use dependent channel blocker. Mol Brain Res 2:21-31.

Walker RJ, Holden-Dye L (1989) Commentary on the evolution of transmitters, receptors and ion channels in invertebrates. Comp Biochem Physiol 93A:25-39.

Weiss S, Drummond GI (1981) Dopamine-sensitive and serotoninsensitive adenylate-cyclase in the gill of Aplysia californica. Mol Pharmacol 20:592-597.

Wichmann T, DeLong MR (1993) Pathophysiology of parkinsonian motor abnormalities. Adv Neurol 60:53-61.

Witz P, Amlaiky N, Plassat J-L, Maroteaux L, Borrelli E, Hen R (1990) Cloning and characterization of a Drosophila serotonin receptor that activates adenylate cyclase. Proc Natl Acad Sci USA 87:8940-8944.

Zheng W, Feng G, Ren D, Eberl DF, Hannan F, Dubald M, Hall LM (1995) Cloning and characterization of a calcium channel $\alpha_{1}$ subunit from Drosophila melanogaster with similarity to the rat brain type D isoform. J Neurosci 15:1132-1143. 